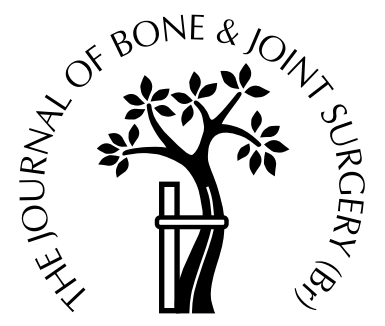

\title{
Retroversion of the humeral head in children with an obstetric brachial plexus lesion
}

\author{
J. A. van der Sluijs, W. J. R. van Ouwerkerk, A. de Gast, \\ P. Wuisman, F. Nollet, R. A. Manoliu \\ From the Vrije Universiteit Medical Centre, Amsterdam, The Netherlands
}

W e undertook a prospective MRI study to measure the retroversion of the humeral head in 33 consecutive infants with a mean age of 1 year 10 months (3 months to 7 years 4 months) who had an obstetric brachial plexus lesion (OBPL). According to a standardised MRI protocol both shoulders and humeral condyles were examined and the shape of the glenoid and humeral retroversion determined.

The mean humeral retroversion of the affected shoulder was significantly increased compared with the normal contralateral side $\left(-28.4 \pm 12.5^{\circ} v-21.5 \pm\right.$ $\left.15.1^{\circ}, p=0.02\right)$. This increase was found only in the children over the age of 12 months. In this group humeral retroversion was $-29.9 \pm 12.9^{\circ}$ compared with $-19.6 \pm 15.6^{\circ}$ in the normal shoulder $(p=0.009)$, giving a mean difference of $10.3^{\circ}(95 \%$ confidence interval 3.3 to 17.3). This finding is of importance when considering the operative treatment for subluxation of the shoulder in children with an OBPL.

J Bone Joint Surg [Br] 2002;84-B:583-7.

Received 7 March 2001; Accepted after revision 20 July 2001

Children with an obstetric brachial plexus lesion (OBPL) may develop secondary deformity of the shoulder. An OBPL which involves the upper roots or trunk of the plexus (C5C6) can cause muscular imbalance around the shoulder with paralysis of the abductors and external rotators leading to a relative dominance of the internal rotators. ${ }^{1}$ As a result, a characteristic secondary deformity develops consisting of a flexion and internal rotation contracture of the arm.

J. A. van der Sluijs, MD, Consultant Orthopaedic Surgeon

A. de Gast, MD, PhD, Consultant Orthopaedic Surgeon

P. Wuisman, MD, PhD, Consultant Orthopaedic Surgeon

Department of Orthopaedic Surgery

W. J. R. van Ouwerkerk, MD, Consultant Orthopaedic Surgeon Department of Neurosurgery

F. Nollet, MD, Consultant Orthopaedic Surgeon

Department of Rehabilitation Medicine

R. A. Manoliu, MD, PhD, Consultant Orthopaedic Surgeon

Department of Radiology

Vrije Universiteit Medical Centre, PO Box 7057, 1007 MB Amsterdam, The Netherlands.

Correspondence should be sent to Dr J. A. van der Sluijs.

(C)2002 British Editorial Society of Bone and Joint Surgery 0301-620X/02/412243\$2.00
Since the first publication by Fairbank in $1913^{2}$ many studies have described secondary deformities of the shoulder in children with OBPL, most often consisting of deformation of the glenoid, alteration of glenoid version and/or posterior subluxation of the humeral head. ${ }^{1,3-7}$

Normal retroversion of the humeral head, subsequently referred to in this study as humeral retroversion, varies with age. It is maximal in infants and decreases to adult values between the ages of 12 and 16 years. ${ }^{8,9}$ Scaglietti ${ }^{10}$ first described an increase in humeral retroversion in children with OBPL. The most likely cause was thought to be muscular imbalance. ${ }^{11,12}$ Nevertheless, some authors suggested that trauma at birth was the main reason. ${ }^{10,13}$ Increased humeral retroversion is important when operative treatment for subluxation of the shoulder in patients with an OBPL is considered. Significantly increased retroversion may, to some extent, compensate for the internal rotation contracture of the arm caused by a posteriorly subluxated humeral head. Correction of humeral subluxation in the presence of increased humeral retroversion may result in a secondary external rotation contracture of the arm. ${ }^{1}$ This possible complication should be considered during preoperative planning.

In order to assess abnormal humeral retroversion in children with an OBPL which may contribute to this complication, we undertook a prospective MRI study of the configuration of the bone and cartilage of the shoulder and humerus.

\section{Patients and Methods}

Between August 1998 and September 2000 we studied prospectively 35 consecutive children with an OBPL. Two were excluded, one on the grounds of age (12 years) and the other because both shoulders were involved. This left 33 children with 33 affected shoulders.

Thirteen infants (group A) had MRI because of a persistent neurological deficit. They were being considered for neurosurgical reconstruction because of poor neurological recovery during the first three months of life. There were seven boys and six girls with a mean age of five months (3 to 9). The left shoulder was affected in seven and the right in six. In the remaining children (group B) MRI was performed because of an internal rotation contracture of the 
Table I. Details of the 33 children with an OBPL

\begin{tabular}{|c|c|c|c|c|c|c|c|c|}
\hline Case & Gender & $\begin{array}{l}\text { Age at } \\
\text { MRI } \\
\text { (mths) }\end{array}$ & $\begin{array}{l}\text { Classification } \\
\text { of } \\
\text { OBPL* }\end{array}$ & Side & $\begin{array}{l}\text { Humeral } \\
\text { retroversion } \\
\text { normal side } \\
\text { (degrees) }\end{array}$ & $\begin{array}{l}\text { Humeral } \\
\text { retroversion } \\
\text { pathological side } \\
\text { (degrees) }\end{array}$ & $\begin{array}{l}\text { Difference } \\
\text { in humeral } \\
\text { retroversion } \\
\text { (degrees) }\end{array}$ & $\begin{array}{l}\text { Glenoid form } \\
\text { at path side } \dagger\end{array}$ \\
\hline \multicolumn{9}{|c|}{ Group A } \\
\hline 1 & F & 2.7 & 2 & $\mathrm{R}$ & -17 & -7 & 10 & 1 \\
\hline 2 & $\mathrm{~F}$ & 3.2 & 1 & $\mathrm{~L}$ & -38 & -16 & 22 & 1 \\
\hline 3 & M & 3.8 & 2 & $\mathrm{R}$ & -29 & -45 & -16 & 1 \\
\hline 4 & M & 4.1 & 1 & $\mathrm{~L}$ & -25 & -17 & 8 & 3 \\
\hline 5 & M & 4.6 & 4 & $\mathrm{R}$ & -16 & -16 & 0 & 2 \\
\hline 6 & $\mathrm{~F}$ & 4.8 & 1 & $\mathrm{~L}$ & -12 & -20 & -8 & 1 \\
\hline 7 & M & 5.0 & 1 & $\mathrm{~L}$ & -26 & -36 & -10 & 1 \\
\hline 8 & M & 5.0 & 1 & $\mathrm{~L}$ & -25 & -19 & 6 & 1 \\
\hline 9 & M & 5.0 & 1 & $\mathrm{~L}$ & -50 & -45 & 5 & 3 \\
\hline 10 & M & 5.4 & 2 & $\mathrm{~L}$ & -26 & -26 & 0 & 2 \\
\hline 11 & $\mathrm{~F}$ & 5.7 & 1 & $\mathrm{R}$ & 10 & -22 & -32 & 2 \\
\hline 12 & F & 5.9 & 2 & $\mathrm{R}$ & -27 & -38 & -11 & 2 \\
\hline 13 & F & 8.7 & 1 & $\mathrm{R}$ & -36 & -30 & 6 & 3 \\
\hline \multicolumn{9}{|c|}{ Group B } \\
\hline 14 & M & 14.5 & 2 & $\mathrm{~L}$ & -12 & -29 & -17 & 1 \\
\hline 15 & $\mathrm{~F}$ & 14.7 & 2 & $\mathrm{R}$ & -26 & -24 & 2 & 3 \\
\hline 16 & M & 17.3 & 1 & $\mathrm{R}$ & 1 & -20 & -21 & 2 \\
\hline 17 & M & 17.5 & 1 & $\mathrm{R}$ & 0 & -20 & -20 & 3 \\
\hline 18 & M & 19.5 & 1 & $\mathrm{R}$ & 10 & -13 & -23 & 3 \\
\hline 19 & $\mathrm{~F}$ & 19.9 & 1 & $\mathrm{~L}$ & -29 & -52 & -23 & 3 \\
\hline 20 & $\mathrm{~F}$ & 21.7 & 1 & $\mathrm{R}$ & -28 & -26 & 2 & 2 \\
\hline 21 & M & 25.3 & 2 & $\mathrm{R}$ & -11 & -35 & -24 & 1 \\
\hline 22 & $\mathrm{~F}$ & 27.4 & 2 & $\mathrm{R}$ & -5 & -20 & -15 & 1 \\
\hline 23 & M & 27.5 & 2 & $\mathrm{R}$ & -16 & -32 & -16 & 2 \\
\hline 24 & $\mathrm{~F}$ & 27.6 & 1 & $\mathrm{R}$ & -22 & -39 & -17 & 2 \\
\hline 25 & $\mathrm{~F}$ & 27.7 & 1 & $\mathrm{~L}$ & -38 & -64 & -26 & 2 \\
\hline 26 & M & 33.6 & 1 & $\mathrm{R}$ & 2 & -37 & -39 & 2 \\
\hline 27 & $\mathrm{~F}$ & 34.8 & 1 & $\mathrm{R}$ & -30 & -28 & 2 & 3 \\
\hline 28 & M & 41.4 & 2 & $\mathrm{~L}$ & -27 & -23 & 4 & 2 \\
\hline 29 & $\mathrm{~F}$ & 43.2 & 1 & $\mathrm{~L}$ & -14 & -17 & -3 & 3 \\
\hline 30 & M & 44.9 & 1 & $\mathrm{R}$ & -29 & -46 & -17 & 3 \\
\hline 31 & M & 51.9 & 2 & $\mathrm{~L}$ & -35 & -17 & 18 & 1 \\
\hline 32 & $\mathrm{M}$ & 75.3 & 1 & $\mathrm{R}$ & -48 & -22 & 26 & 1 \\
\hline 33 & $\mathrm{~F}$ & 88.1 & 2 & $\mathrm{R}$ & -35 & -35 & 10 & 2 \\
\hline
\end{tabular}

* 1, C5/C6 lesion; $2, \mathrm{C} 5 / \mathrm{C} 6 / \mathrm{C} 7$ lesion; 4, total lesion according to Narakas ${ }^{14}$

$\dagger 1$, concave-flat; 2 , convex; 3 , biconcave according to Birch ${ }^{1}$

arm. There were 11 boys and nine girls with a mean age of two years ( 1 year 2 months to 7 years 4 months). They had a persistent unilateral OBPL with secondary deformities of the shoulder. Details of both groups are given in Table I.

The severity of the neurological deficit was determined according to the system of classification described by Narakas.

In all children both shoulders and elbows were examined by MRI (Magnetom 1.5 T Vision; Siemens, Erlangen, Germany). Children aged under five years were given pethidine, droperidol and chlorpromazine intramuscularly. During sedation they were monitored by ECG, measurement of the oxygen saturation and by video. A FISP threedimensional pulse acquisition sequence (repetition time, 25 msec; time to echo, $10 \mathrm{msec}$; flip angle $40^{\circ}$ ) with $1.5 \mathrm{~mm}$ partitions was used. Both shoulders were measured in the axial plane, at the mid-glenoid level, and at the distal humeral condyles. All measurements were made on images in digital format using post-processing software (Radworks 5.0; Applicare Medical Imaging BV, Zeist, The Netherlands).

We used two established methods of measurement. The form of the glenoid was classified qualitatively as concaveflat, convex or biconcave as defined by Birch ${ }^{1}$ and humeral retroversion was measured according to the method of Scaglietti. ${ }^{10}$ For this, MRI of both the shoulder and elbow was necessary. Measurements focused on both the cartilaginous head and the structure of the distal humeral condyles since in infants these skeletal structures are mostly cartilaginous (Fig. 1).

The difference in humeral retroversion between the pathological and normal side was studied. The results were expressed as the mean \pm SD. For differences between the normal and affected sides a 95\% confidence interval (CI) was given. The relationship between age and retroversion was described using the Pearson correlation coefficient. The statistical significance of the differences in retroversion between the pathological and normal side was tested using the paired two-sided Student $t$-test.

\section{Results}

Normal side. The mean humeral retroversion of the normal shoulder was $-21.5 \pm 15.1^{\circ}$ (Table I and Fig. 2a). Statis- 


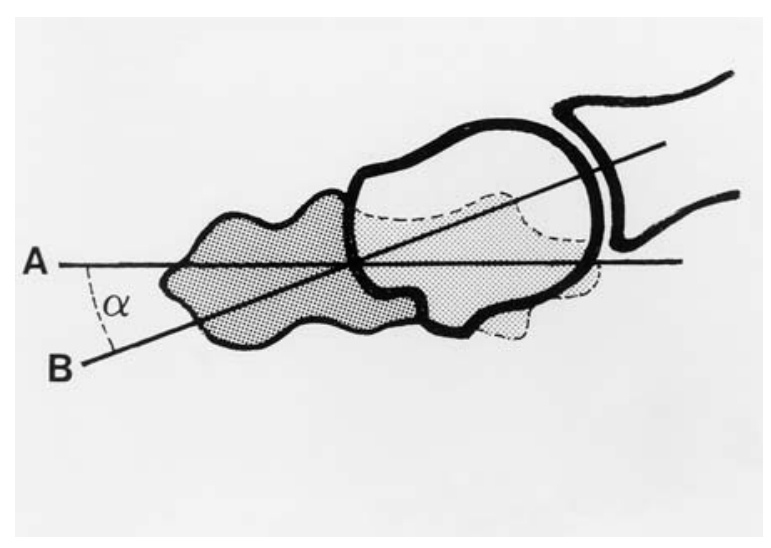

Fig. 1

Diagram showing the method of measurement of humeral retroversion according to Scaglietti. ${ }^{10} \mathrm{~A}$ is the line through the medial and lateral humeral condyles and $\mathrm{B}$ the line through the longest diameter of the humeral head. Retroversion is the angle between A and $\mathrm{B}$.

tically, there was a weak negative relationship to age ( $\mathrm{r}=$ -0.23 ).

Pathological side. The mean humeral retroversion of all 33 affected shoulders was significantly increased $(p=0.02)$ compared with the normal contralateral side $\left(-28.42 \pm 12.5^{\circ}\right.$ $v-21.5 \pm 15.1^{\circ}$; $95 \%$ CI -0.1 to -13.7 ; Fig. 3 ).

Analysis by group showed this difference to be present only in group $\mathrm{B}$, that is in children over the age of 12 months. In this group the mean humeral retroversion of the affected shoulder was $-29.9 \pm 12.9^{\circ}$ compared with $-19.6 \pm$ $15.6^{\circ}$ in the normal shoulder $(\mathrm{p}=0.009)$, giving a mean difference of $10.3^{\circ}\left(95 \%\right.$ CI 3.3 to $\left.17.3^{\circ}\right)$ between them. Differences of up to $39^{\circ}$ were found. There was no significant difference in retroversion in children under the age of 12 months (group A). In this group humeral retroversion of the affected shoulder was $-25.9 \pm 11.9^{\circ}$ and that of the normal shoulder $-24.4 \pm 14.3^{\circ}$.

The difference in humeral retroversion between the nor-

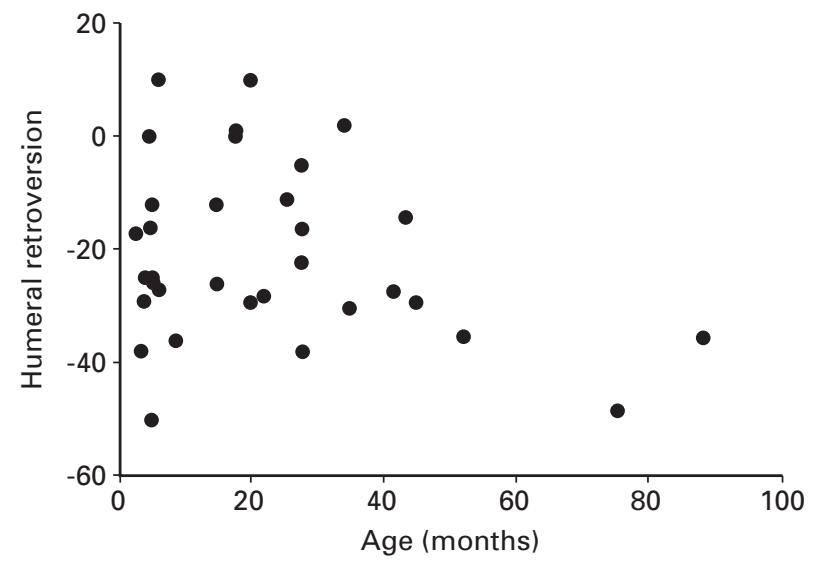

Fig. 2a mal and affected sides was not significantly related to gender, type of OBPL or the presence of an abnormal glenoid.

\section{Discussion}

Scaglietti ${ }^{10}$ first drew attention to abnormal humeral retroversion, which he termed declination, in children with an OBPL, but as with other authors, ${ }^{1}$ he did not give quantitative data on its prevalence. ${ }^{11-13}$ Edelson, ${ }^{8,9}$ measuring retroversion according to Scaglietti on bony landmarks, which is a technique comparable to that used to estimate femoral anteversion, ${ }^{15}$ found a large variability in normal shoulders $\left(\mathrm{SD} 8^{\circ}\right)$. In his studies retroversion decreased with age from a mean of $65^{\circ}$ up to four years of age to a mean of $30^{\circ}$ by the age of 16 years.

In our study retroversion was measured according to Scaglietti ${ }^{10}$ on cartilaginous rather than on osseous structures since in infants these elements are predominantly cartilaginous. By contrast with radiography, MRI allowed a detailed analysis of the mainly cartilaginous structures. Humeral retroversion can be measured by other imaging techniques such as standard radiography, but MRI is superior and avoids exposure to radiation.

Our results differ from those of Edelson ${ }^{8,9}$ in that retroversion in our younger group (0 to 4 years) is less, with a mean $-21^{\circ}$ compared with $-65^{\circ}$ found by Edelson. This difference can be explained by his use of different landmarks. Whereas Edelson found a significant negative relationship to age we noted only a weak non-significant negative relationship between retroversion on the normal side and age, perhaps because only three children in our study were older than four years.

We have shown that, in some children with an OBPL, humeral retroversion of the affected shoulder is significantly increased compared with the normal side. We agree with other authors that muscular imbalance and lack of derotating forces around the shoulder are the most likely

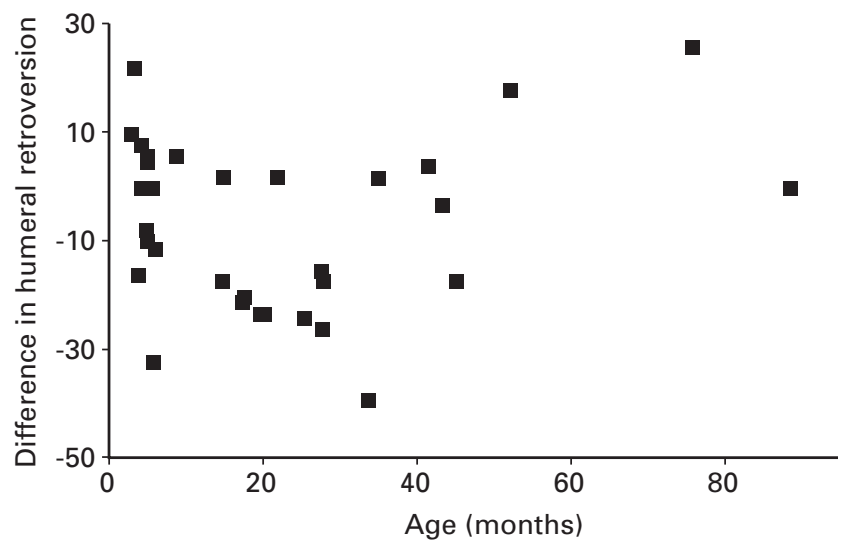

Fig. $2 b$

Graph showing a) the relationship between age and humeral retroversion in the normal shoulder and b) the difference in retroversion (pathological side minus normal side). It is negative if retroversion of the pathological side is larger. 


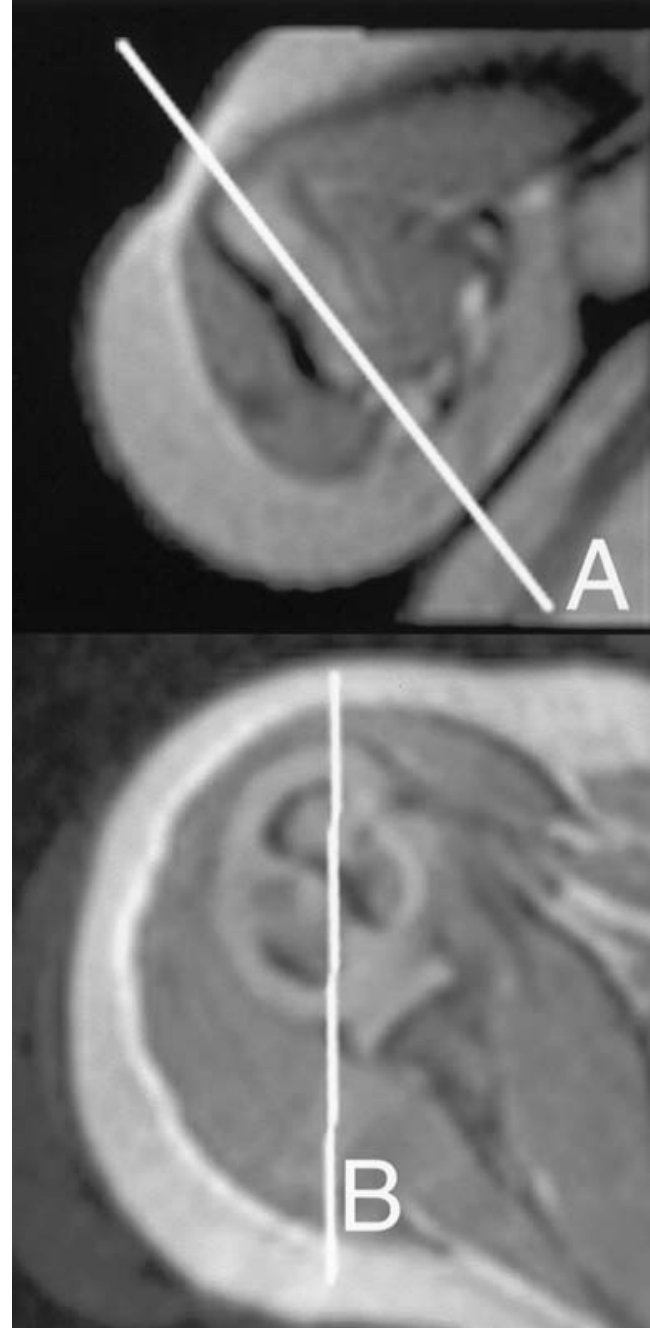

Fig. 3a

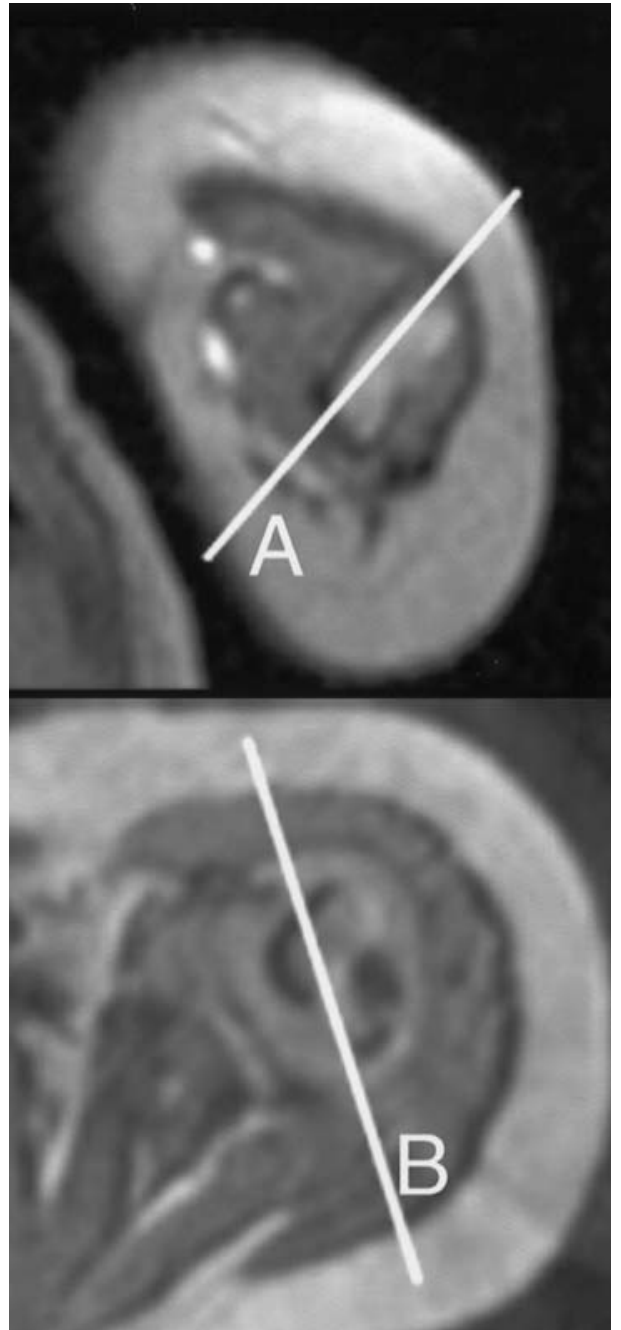

Fig. $3 b$

Case 25. MR scans showing increased humeral retroversion. Retroversion is the angle between the lines A and B. For the right normal shoulder (a) retroversion is $-38^{\circ}$ and for the affected shoulder (b) with subluxation and deformity of the glenoid, it is $-64^{\circ}$.

causes of the increased retroversion. ${ }^{11,12}$ In our study the differences in retroversion between the normal and affected side were mainly in children over the age of one year (group B). The normal decrease in retroversion, as described by Edelson, may be inhibited in some children with an OBPL.

Some authors have suggested that the birth trauma which caused the OBPL is responsible for the difference in humeral retroversion. ${ }^{10,13}$ In our study no trauma-related changes in the shoulders were found on MRI. Lateral flexion or traction of the head causes OBPL, but in experimental studies only extension and adduction of the shoulder were able to cause a humeral epiphyseal fracture. ${ }^{16,17}$ These movements do not occur during birth. The persistence of humeral retroversion in a posteriorly subluxated shoulder enhances subluxation of the humeral head, but it can have a compensatory functional effect by increasing the external rotation of the arm. When the humeral head is reduced operatively, however, an external rotation contracture of the arm may develop. Birch ${ }^{1}$ found this in onethird of 86 children in whom subluxated shoulders were surgically reduced. An external rotation contracture can cause problems since most activities of daily living require internal rotation. ${ }^{18}$ Postoperative stiffness is also encountered in shoulders which are reduced by operation. We believe that the combined effect of increased retroversion and the long-standing postoperative stiffness of the operated shoulder immobilised in external rotation, causes an external rotation contracture in some children with an OBPL. This can be treated by a derotational osteotomy ${ }^{1,10}$ which should be performed at least one year after reduction of the shoulder in order to allow time for recovery of function.

Increased humeral retroversion is present in some children with an OBPL and is not related to the type of OBPL or deformities of the shoulder. This finding is of importance 
when operative treatment for subluxation of the shoulder is being considered in these children.

No benefits in any form have been received or will be received from a commercial party related directly or indirectly to the subject of this article.

\section{References}

1. Birch R. Birth lesions of the brachial plexus. In: Birch R, Bonney $G$ Wynn Parry CB, eds. Surgical disorders of the peripheral nerves. London: Churchill Livingstone, 1998:209-33.

2. Fairbank HAT. Birth palsy: subluxation of the shoulder joint in infants and young children. Lancet 1913;1:1217-23.

3. Beischer AD, Simmons TD, Torode IP. Glenoid version in children with obstetric brachial plexus palsy. $J$ Pediatr Orthop 1999;19:359-61.

4. Gudinchet F, Maeder P, Oberson JC, Schnyder P. Magnetic resonance imaging of the shoulder in children with brachial plexus birth palsy. Pediatr Radiol 1995;25:125-8.

5. Pearl ML, Edgerton BW. Glenoid deformity secondary to brachial plexus birth palsy. J Bone Joint Surg [Am] 1998;80-A:659-67.

6. Torode I, Donnan L. Posterior dislocation of the humeral head in association with obstetric paralysis. J Pediatr Orthop 1998;18:611-5.

7. Waters PM, Smith GR, Jaramillo D. Glenohumeral deformity secondary to brachial plexus birth palsy. J Bone Joint Surg [Am] 1998;80-A:668-77.
8. Edelson G. The development of humeral head retroversion. J Shoulder Elbow Surg 2000;9:316-8.

9. Edelson G. Variations in the retroversion of the humeral head. $J$ Shoulder Elbow Surg 1999;8:142-5.

10. Scaglietti O. The obstetrical shoulder trauma. Surg Gynecol Obstet 1938;66:868-77.

11. Goddard $\mathbf{N}$. The development of the proximal humerus in the neonate with particular reference to bony lesions around the shoulder. In: Tubiana R, ed. The Hand. Vol. IV. Philadelphia: W. B. Saunders, 1993:624-31.

12. Gilbert A. Obstetrical brachial plexus palsy. In: Tubiana $\mathrm{R}$, ed. The Hand. Vol. IV. Philadelphia: W. B. Saunders, 1993:575-601.

13. Zancolli EA, Zancolli ER Jr. Palliative surgical procedures in sequelae of obstetric palsy. Hand Clin 1988;4:643-69.

14. Narakas AO. Obstetrical brachial plexus injuries. In: Lamb D, ed. The paralysed hand. Edinburgh: Churchill Livingstone, 1987:116-35.

15. Murphy SB, Simon SR, Kijewski PK, Wilkinson RH, Griscom NT. Femoral anteversion. J Bone Joint Surg [Am] 1987;69-A:1169-76.

16. Sever JW. Obstetric paralysis: its etiology, pathology, clinical aspects and treatment, with a report of 470 cases. Am J Dis Child 1916;12:541-78.

17. Platt H. Opening remarks on birth paralysis. J Orthop Surg 1920;2:272-94

18. Pearl M, Harris S, Lippit S, et al. A system for describing positions of the humerus relative to the thorax and its use in the presentation of several functionally important arm positions. J Shoulder Elbow Surg 1992;1:113-8. 